\title{
Identification and Characterization of Rabbit Hemorrhagic Disease Virus Genetic Variants Isolated in Korea
}

\author{
Jae-Ku OEM ${ }^{1) *}$, Kwang-Nyeong LEE ${ }^{1)}$, In Soon $\mathrm{ROH}^{1)}$, Kyoung-Ki LEE ${ }^{1)}$, Seong-Hee KIM ${ }^{1)}$, Hye-Ryoung $\mathrm{KIM}^{1)}$, \\ Choi-Kyu PARK ${ }^{1)}$ and Yi-Seok JOO ${ }^{1)}$ \\ ${ }^{1)}$ National Veterinary Research and Quarantine Service, Ministry of Agriculture, Anyang, Republic of Korea
}

(Received 6 April 2009/Accepted 2 July 2009)

ABSTRACT. Nine isolates of rabbit hemorrhagic disease virus (RHDV) were used for the genetic characterization of RHDV strains collected from rabbits in Korea between 2006 and 2008. A phylogenetic analysis of the complete VP60 region was performed and the sequences were divided mainly into two groups. The one group consisted of original RHDV and the other contained antigenic variant strain known as RHDVa strains. Most of the Korean isolates clustered with Chinese RHDV strains and belonged to the RHDVa subtype. A comparison of the amino acid sequences among RHDVa strains and original RHDV strains revealed significant substitutions of two amino acids in the A region, two in the $\mathrm{B}$ region, two in the $\mathrm{F}$ region, and nine amino acids in the $\mathrm{E}$ region. Taken together, the recent RHDVa strains have gradually replaced the original RHDV and are the predominant strains in Korea.

KEY WORDS: Phylogenetic analysis, RHDV.

Rabbit hemorrhagic disease virus (RHDV) is an icosahedral, non-enveloped, positive-sense, single-stranded RNA virus within the genus Lagovirus, family Caliciviridae [13, 17]. The viral genome is composed of approximately $7.4 \mathrm{~kb}$ and a subgenomic RNA of approximately $2.2 \mathrm{~kb}$, which codes for VP60 [14]. The RHDV capsid consists of a shell (S) domain formed by the N-terminal portion and a protrusion $(\mathrm{P})$ domain formed by the C-terminal portion. The $\mathrm{P}$ domain can be subdivided into $\mathrm{P} 1$ and $\mathrm{P} 2$ subdomains. Six distinct regions (A to $\mathrm{F}$ ) can be distinguished in the protein; regions $\mathrm{C}$ and $\mathrm{E}$ are located in the exposed $\mathrm{P} 2$ subdomain and display the greatest genetic variation [16]. RHDV is highly contagious to both wild and domestic rabbits. Characteristic pathological lesions are found in the liver, trachea, and lungs of infected rabbits and the animals die within 12 to $72 \mathrm{hr}$ due to severe hepatitis and hemorrhages [5, 6].

Rabbit hemorrhagic disease (RHD) was first reported in China in 1984 [10] and rapidly became endemic in most parts of the world. Other viruses in this group include the European brown hare syndrome virus (EBHSV), a highly pathogenic virus of hares, and rabbit calicivirus (RCV). $\mathrm{RCV}$ is a nonpathogenic variant reported in Italy that might be protective against the pathogenic virus [2]. Pathogenic but antigenic variant strains, named RHDVa, were also reported in Germany, Italy, France, and the United States [3, $9,12,18]$. The RHDVa strains are characterized by molecular and antigenic differences with respect to the previous RHDV strains.

RHDV was reported in Korea in 1985 following the importation of rabbit fur from China [1], but RHD has not

\footnotetext{
* Correspondence to: Oem, J.-K., Viral Disease Diagnostic Laboratory, Animal Disease Diagnostic Center Division, National Veterinary Research and Quarantine Service, 480 Anyang-6Dong, Anyang, 430-824, Korea.

e-mail: jku0622@nvrqs.go.kr
}

been reported in Korea since its first occurrence. While a few studies have been performed on the basis of gene sequences, the molecular epidemiology of RHDV has not been well characterized. The aim of this study was to identify the strains circulating in Korea and determine whether the Korean isolates are related to the RHDVa subtype reported previously $[9,12]$.

Twenty-four samples of rabbit liver, spleen, and lung were collected over a period of 36 months from dead rabbits in several provinces of Korea. The nine RHDV-suspected samples were confirmed using RT-PCR. The total viral RNA was extracted from samples of liver, lung, and spleen using the RNeasy Mini Kit (Qiagen, Hilden, Germany) following the manufacturer's instructions. RT-PCR was performed in a one-tube system using previously described primers to amplify a 1740-bp region of the genome encoding the capsid protein VP60: RHDV VP60F, 5'-ATGGAGGGCAAAGCCCGCACAGCG-3' (nt 5305-5328) and RHDV VP60R, 5'-AATTCAGACATAAGAAAAGCCATTG-3' (nt 7025-7047) [4]. The amplified gene was purified using an agarose gel DNA extraction kit (INtRON, Seongnam, Korea) and further cloned into PGEM-T vector (Promega, Madison, WI, U.S.A.) according to the manufacturer's instructions. Automated nucleotide sequencing of the VP60 gene insert was performed using an ABI 3130XL genetic analyzer with the BigDye ${ }^{\circledR}$ Terminator cycle sequencing kit (Applied Biosystems, Foster City, CA, U.S.A.). The nucleotides at all positions were confirmed by three or more independent sequencing reactions in both directions. The published RHDV sequences were retrieved from GenBank for phylogenetic analyses (Table 1).

The complete VP60 sequence of nine isolates were aligned with 25 reported RHDV sequences obtained from GenBank using Bioedit software (Ibis Biosciences, Carlsbad, CA, U.S.A.). The tree was rooted with RCV as an out- 
Table 1. Korean RHDV sequences and published sequences used in the phylogenetic analysis

\begin{tabular}{|c|c|c|c|c|c|c|c|}
\hline \multicolumn{4}{|c|}{ Korean Strains } & \multicolumn{4}{|c|}{ Published Sequences } \\
\hline Description & $\begin{array}{l}\text { GenBank } \\
\text { Accession } \\
\text { Number }\end{array}$ & $\begin{array}{l}\text { Year } \\
\text { Isolated }\end{array}$ & Province & Description & $\begin{array}{l}\text { Country of } \\
\text { Origin }\end{array}$ & $\begin{array}{c}\text { Year } \\
\text { Isolated }\end{array}$ & $\begin{array}{l}\text { Accession } \\
\text { Number }\end{array}$ \\
\hline 06Q24-2 & - & 2006 & Junnam & whn/china/01/2005 & China & 2005 & DQ069280 \\
\hline 06Q48-2 & - & 2006 & Chungnam & 05-01/France & France & 2005 & AM085133 \\
\hline 06D32-1 & & 2006 & Gyeonggi & whn/china/02/2005 & China & 2005 & DQ069281 \\
\hline 06Q755 & - & 2006 & Chungbuk & Ireland18/Ireland & Ireland & - & AY928268 \\
\hline 07Q92-1 & - & 2007 & Daejun & JX/CHA/97 & China & 1997 & DQ205345 \\
\hline 08Q121 & - & 2008 & Gyeonggi & complete & Spain & 1989 & Z24757 \\
\hline 08Q221 & - & 2008 & Gyeonggi & $\mathrm{CD} /$ China & China & - & AY523410 \\
\hline $08 Q 712$ & - & 2008 & Incheon & NJ/China/1985 & China & 1985 & AY269825 \\
\hline KV0801 & FJ212322 & 2008 & & TP/China & China & - & AF543761 \\
\hline & & & & $\mathrm{AST} / 89$ & Spain & 1989 & Z49271 \\
\hline & & & & UT-01 & USA & 2001 & EU003582 \\
\hline & & & & NY-01 & USA & 2001 & EU003581 \\
\hline & & & & Italy-90 & Italy & 1990 & EU003579 \\
\hline & & & & RamsayIsland & Germany & - & EF363035 \\
\hline & & & & Bahrain & Bahrain & 2001 & DQ189077 \\
\hline & & & & RHDV-BS89 & Italy & 1989 & X87607 \\
\hline & & & & RHDV-SD & France & - & Z29514 \\
\hline & & & & Haute-Saone/98 & France & 1998 & U49726 \\
\hline & & & & $\mathrm{MC} / 89$ & Spain & 1989 & L48547 \\
\hline & & & & $\mathrm{RCV}$ & Italy & 1996 & X96868 \\
\hline
\end{tabular}

“-” indicates no GenBank accession number or no isolated year.

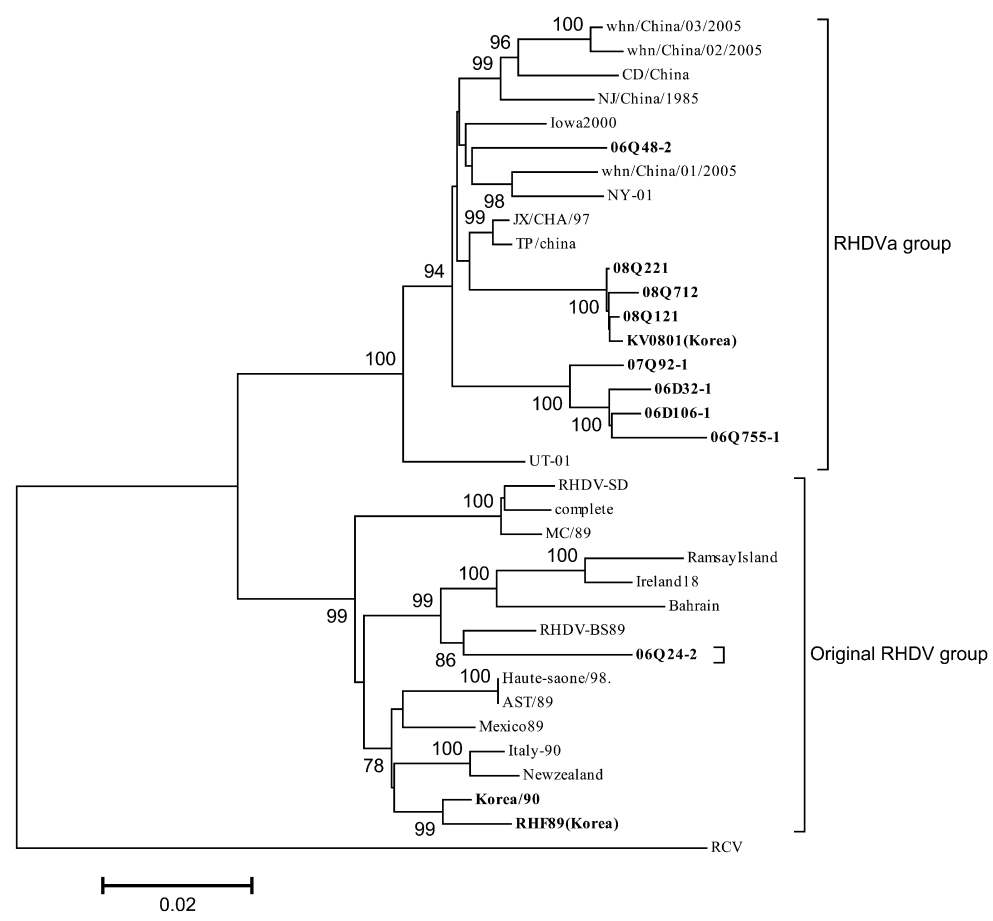

Fig. 1. Phylogenetic analysis of VP60 nucleotide sequences of diverse isolates. The nucleotide sequences of 34 RHDV isolates were aligned using the Bioedit program and Mega 3 software. One thousand bootstrap replicates were subjected to nucleotide sequence distance and neighbor-joining methods, and the consensus phylogenetic tree is shown. All bootstrap values are displayed above the tree branches and only bootstrap values $>70 \%$ are shown. 
(A)

\begin{tabular}{|c|c|}
\hline & $\ldots 1 \ldots 1_{10}^{10} \ldots 1 \ldots 1^{20}$ \\
\hline WJ/China/1985 & DPGVWAATS SUTAENS SASWA \\
\hline who/China/03/2005 & $\ldots \ldots \ldots \ldots . . . \ldots . . . \ldots$ \\
\hline who/China/02/2005 & $\ldots \ldots \ldots \ldots \ldots$ \\
\hline Cn/China & $\ldots \ldots \ldots \ldots \ldots$ \\
\hline Lowa 2000 & $\cdots \ldots \ldots \ldots \ldots$ \\
\hline WT-01 & $\ldots \ldots \ldots \ldots \ldots$ \\
\hline whon/China/01/2005 & $\cdots \ldots$ \\
\hline DX/CHA $/ 97$ & 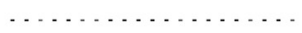 \\
\hline rP/china & $\cdots \ldots \ldots$ \\
\hline UT-01 & $\ldots \ldots \ldots$ \\
\hline 080221 & 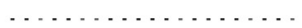 \\
\hline $07092-1$ & $\ldots \ldots \ldots \ldots$ \\
\hline $06032-1$ & $\ldots \ldots \ldots \ldots \ldots$ \\
\hline 080712 & 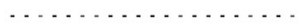 \\
\hline Kr0801(Korea) & $\ldots \ldots \ldots \ldots \ldots \ldots$ \\
\hline $06048-2$ & $\ldots \ldots \ldots \ldots \ldots$ \\
\hline 080121 & $\cdots \ldots \ldots \ldots \ldots \ldots$ \\
\hline $060755-1$ & $\ldots \ldots \ldots \ldots$ \\
\hline $060106-1$ & $\ldots \ldots \ldots \ldots \ldots$ \\
\hline complete & $\ldots \ldots \mathbf{T} \ldots \ldots \ldots$. \\
\hline RamsayIsland & $\ldots \ldots T \ldots \ldots$ \\
\hline WC/89 & $\boldsymbol{T} \mathbf{T}$ \\
\hline Ireland18 & $\ldots$ T. \\
\hline EHWV-SD & $\ldots \ldots \mathbf{T} \ldots \ldots \ldots \mathbf{I}$ \\
\hline Bahrain & $\ldots \ldots \mathbf{T} \ldots \ldots \ldots$ \\
\hline RHDV-BS 89 & $\ldots \ldots \mathbf{T} \ldots \ldots$ \\
\hline Newzealand & $\ldots \ldots$ T $\ldots I \ldots \ldots$ I. \\
\hline AST / 89 & $\ldots \ldots \mathbf{T} \ldots \mathbf{I} \ldots \ldots$ I \\
\hline Italy -90 & $\ldots \ldots$. . . . . . . . . I \\
\hline Wexico 89 & $\ldots \ldots$ T. . I . . . . I I \\
\hline Haute-saone/98. & $\ldots \ldots$ T $\ldots I \ldots \ldots$ I \\
\hline Korea/90 & $\ldots \ldots$ T. . I . . . . . I I \\
\hline BHF 89 (Korea) & $\ldots \ldots T \ldots I \ldots I_{1}$ \\
\hline $06024-2$ & $\ldots$ T. $\ldots$ I \\
\hline
\end{tabular}

(B)

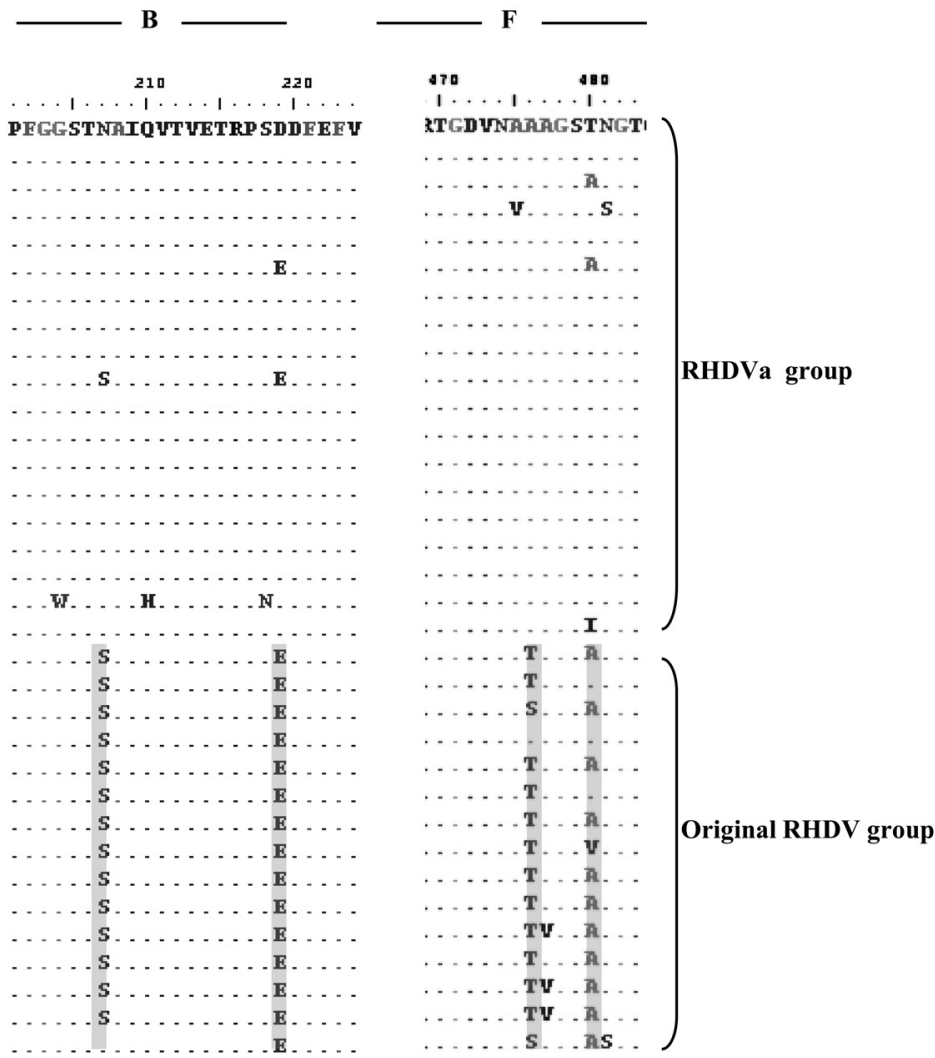

(D)

E

NJ/China/1985

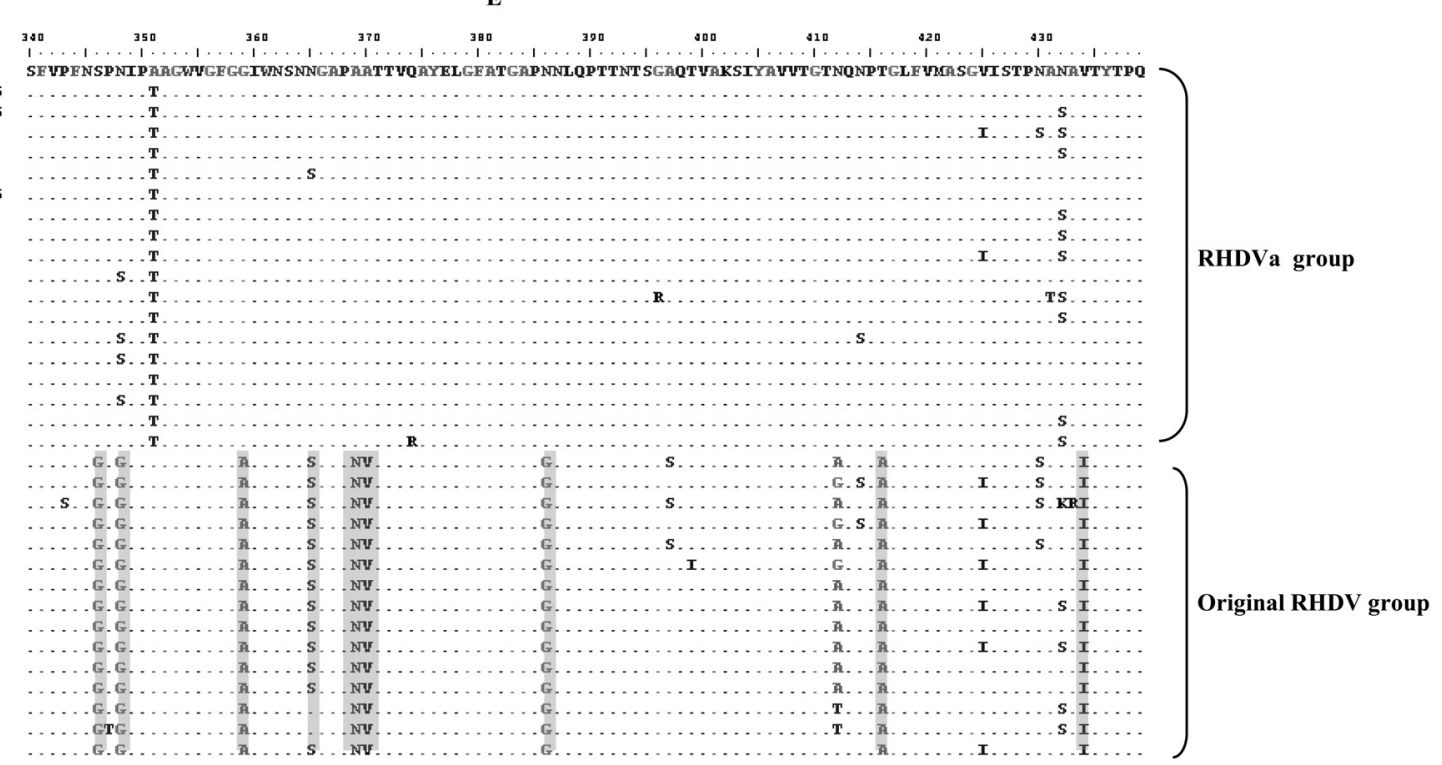
whn/China/02/2005

CnfChina

Iowa2000

win/China/01/200

JX/CHR $/ 9$ ?

TP/china

UT-01

$07092-1$

06D32-1

080712

kvos01(Korea

06048-2

080121

060755-1

$06 \mathrm{D106-1}$

complete

RamsayIsland

I

Prov-sD

Bahrain

RHDV-BS8 9

Newzeal

Italy-90

Mexico 89

Haute-saone/ 98

Korea/90

06024-2

Fig. 2. Amino acid sequence alignment of the hypervariable region of VP60 among the original RHDV and RHDVa. Amino acid residues identical to those of the NJ/China/1985 strain are indicated with dots. The capsid protein region A (A), B (B), F (C), and E (D) are marked according to the nomenclature of Neil (1992). For abbreviations, see Table 1. 
group. A phylogenetic analysis based on the complete VP60 sequence was conducted using the Bioedit software and Molecular Evolutionary Genetics Analysis (MEGA) 3.1 software with bootstrap values calculated from 1000 replicates [7]. The phylogenetic algorithm used for the building of the tree was Neighbor-joining method.

RHDV strains can be divided into two major clusters, the original RHDV subtypes and the RHDVa subtypes. The clustering is demonstrated clearly in the phylogenetic tree illustrated in Fig. 1. The alignment indicated that the 06Q24-1 strain clustered with the original RHDV group, whereas the remaining eight isolates clustered with the RHDVa group. With the exception of the 06Q24-1 strain, which was $10.3 \%$ divergent from the other Korean isolates, the new isolates exhibited a maximum nucleotide difference of $5.9 \%$, indicating only limited variation among most of the Korean isolates analyzed. The new isolates also showed a maximum difference of $9.7 \%$ compared to previous Korean isolates. These data are in agreement with the genetic diversity reported previously $[8,9,11]$. Among the eight isolates in the RHDVa group, seven clustered together on a separate branch within the RHDVa group, whereas the 06Q48-2 strain clustered with NY-01 and whn/China/01/2005. This result revealed that recent RHDVa strains are predominant in Korea and are circulating in rabbit populations, although the original RHDV and RHDVa strains were isolated together in 2006.

The deduced amino acid sequences of the complete VP60 gene of original RHDV and RHDVa subtype strains were aligned using Bioedit software according to the nomenclature of Neil (1992). Amino acid changes were found clustered between residues 1 and 20 (region A), 200 and 220 (region B), 340 and 440 (region E), and 470 and 490 (region F) (Fig. 2). The substitutions were found at two positions of region $\mathrm{A}$ (amino acid residues 7 and 20), two sites of region $\mathrm{B}$ (residues 207 and 219), and two sites of region F (residues 476 and 480 ). The highest variability within the complete VP60 was observed between amino acids 340 and 440 according to previous reports $[3,18]$. Nine distinct amino acid substitutions were found within this antigenic epitope between the original RHDV and RHDVa subtypes in multiple sequence alignments of 34 RHDV isolates.

The clustering into several genogroups is correlated more with the year of isolation than the geographic location $[8,9$, 15]. Both the original RHDV and RHDVa strains were identified together in 2006, while only RHDVa strains were identified in 2007 and 2008. From these results, pinpointing where RHDVa originated from, or determining why RHDVa replaced original RHDV in Korea, is impossible. However, RHDVa has rapidly replaced the RHDV strains and is the predominant type in almost all parts of Korea.

RHD was first detected in the 1980s, but its origins are not completely understood. RHDV is currently spreading throughout Europe, the United States, and Asia, despite the implementation of an effective vaccine. In Korea, the first case was diagnosed in 1985. Due to a rapid measures and a vaccination program, the number of outbreaks decreased rapidly, but RHDV still occurs occasionally in Korea.

RHD is an extremely contagious and often fatal viral disease of domestic and wild rabbits $[4,19]$. The highest morbidity and mortality rates have been observed in adult rabbits from naïve populations. Young rabbits less than 8 weeks old are less likely to become ill or die [20]. In most rabbit farms, RHDV-infected rabbits have developed a fever and died suddenly within 2 days. High morbidity and mortality were also observed in adult rabbits, but young rabbits have exhibited lower death rates in Korea.

Most of the Korean isolates belong to the RHDVa subtype, but how or when the strains were introduced to Korea is not clear. Continuous monitoring and molecular analysis of the RHDV strains present in Korea should be performed. Moreover, both new and established vaccines should be evaluated through challenging with RHDVa.

ACKNOWLEDGMENT. This study was supported by the National Veterinary Research and Quarantine Service, Ministry of Agriculture, Anyang, Republic of Korea.

\section{REFERENCES}

1. An, S.H., Kim, B.H., Lee, J.B., Song, J.U., Park, B.K., Kwon, Y.B., Jung, J.S. and Lee, Y.S. 1998. Studies on Picornavirus hemorrhagic fever (tentative name) in rabbit. 1. Physicochemical properties of the causative virus. Res. Rep. Rural Dev. Adm. 30: $55-61$.

2. Capucci, L., Fusi, P., Lavazza, A., Pacciarini, M.L. and Rossi, C. 1996. Detection and preliminary characterization of a new rabbit calicivirus related to rabbit hemorrhagic disease virus but nonpathogenic. J. Virol. 70: 8614-8623.

3. Capucci, L., Fallacara, F., Grazioli, S., Lavazza, A., Pacciarini, M.L. and Brocchi, E. 1998. A further step in the evolution of rabbit hemorrhagic disease virus: the appearance of the first consistent antigenic variants. Virus Res. 58: 115-126.

4. Farnós, O., Rodríguez, D., Valdés, O., Chiong, M., Parra, F., Toledo, J.R., Fernández, E., Lleonart, R. and Suárez, M. 2007. Molecular and antigenic characterization of rabbit hemorrhagic disease virus isolated in Cuba indicates a distinct antigenic subtype. Arch. Virol. 152: 1215-1221.

5. Fuchs, A. and Weissenb-ck, H. 1992. Comparative histopathological study of rabbit haemorrhagic disease (RHD) and European brown hare syndrome (EBHS). J. Comp. Pathol. 107: $103-113$.

6. Gregg, D.A., House, C., Meyer, R. and Berninger, M. 1991. Viral haemorrhagic disease of rabbits in Mexico: epidemiology and viral characterization. Rev. Sci. Tech. 10: 435-451.

7. Kumar, S., Tamura, K. and Nei, M. 2004. MEGA3: integrated software for molecular evolutionary genetics analysis and sequence alignment. Brief Bioinform. 5: 150-163.

8. Le Gall-Reculé, G., Zwingelstein, F., Laurent, S., de Boisséson, C., Portejoie, Y. and Rasschaert, D. 1999. Molecular epidemiology of rabbit haemorrhagic disease virus outbreaks in France during 1988 to 1995. J. Gen. Virol. 79: 11-16.

9. Le Gall-Reculé, G., Zwingelstein, F., Laurent, S., De Boisséson, C., Portejoie, Y. and Rasschaert, D. 2003. Phylogenetic analysis of rabbit haemorrhagic disease virus I France between 1993 and 2000, and the characterization of RHDV antigenic variants. Arch. Virol. 148: 65-81.

10. Liu, S.J., Xue, H.P., Pu, B.Q. and Quian, N.H. 1984. A new 
viral disease in rabbits. Anim. Husbandry Vet. Med. 16: 253255 .

11. Matiz, K., Ursu, K., Kecskeméti, S., Bajmócy, E. and Kiss, I. 2006. Phylogenetic analysis of rabbit haemorrhagic disease virus (RHDV) strains isolated between 1988 and 2003 in eastern Hungary. Arch. Virol. 151: 1659-1666.

12. McIntosh, M.T., Behan, S.C., Mohamed, F.M., Lu, Z., Moran, K.E., Burrage, T.G., Neilan, J.G., Ward, G.B., Botti, G., Capucci, L. and Metwally, S.A. 2007. A pandemic strain of calicivirus threatens rabbit industries in the Americas. Virol. J. 4: 96-108.

13. Meyers, G., Wirblich, C. and Thiel, H.J. 1991a. Genomic and subgenomic RNAs of rabbit hemorrhagic disease virus are both protein-linked and packaged into particles. Virology 184: 677686.

14. Meyers, G., Wirblich, C. and Thiel, H.J. 1991b. Rabbit hemorrhagic disease virus-molecular cloning and nucleotide sequencing of a calicivirus genome. Virology 184: 664-676.

15. Moss, S.R., Turner, S.L., Trout, R.C., White, P.J., Hudson, P.J., Desai, A., Armesto, M., Forrester, N.L. and Gould, E.A. 2002. Molecular epidemiology of rabbit haemorrhagic disease virus. J. Gen. Virol. 83: 2461-2467.

16. Neil, J.D. 1992. Nucleotide sequence of the capsid protein gene of two serotypes of San Moguel sea lion virus: identification of conserved and non-conserved amino acid sequences among calicivirus capsid proteins. Virus Res. 24: 211-222.

17. Ohlinger, R.F., Haas, B., Meyers, G., Weiland, F. and Thiel, H.J. 1990. Identification and characterization of the virus causing rabbit haemorrhagic disease. J. Virol. 64: 3331-3336.

18. Schirrmeier, H., Reimann, I., K-llner, B. and Granzow, H. 1999. Pathogenic, antigenic and molecular properties of rabbit haemorrhagic disease virus (RHDV) isolated from vaccinated rabbits: detection and characterization of antigenic variants. Arch. Virol. 144: 719-735.

19. van de Bildt, M.W.G., van Bolhuis, G.H., van Zijderveld, F., van Riel, D., Drees, J.M., Osterhaus, A.D.M.E. and Kuiken, T. 2006. Confirmation and phylogenetic analysis of rabbit hemorrhagic disease virus in free-living rabbits from the Netherlands. J. Wildl. Dis. 42: 808-812.

20. Xu, E.J. and Chen, W.X. 1989. Viral hemorrhagic disease in rabbits. Vet. Res. Commun. 13: 205-212. 